\title{
Modeling the effects of abiotic and biotic factors on the depth distribution of Fucus vesiculosus in the Baltic Sea
}

\author{
Nikolaos Alexandridis*, Andreas Oschlies, Martin Wahl \\ Helmholtz Centre for Ocean Research Kiel (GEOMAR), Düsternbrooker Weg 20, 24105 Kiel, Germany
}

\begin{abstract}
The conspicuous retreat of the key species Fucus vesiculosus from the deeper parts of its former distribution area in the Baltic Sea has triggered extensive research on the factors that control its growth. Based on recently obtained knowledge on a large number of potential drivers, we developed a numerical model incorporating effects of abiotic factors on the physiological functions of photosynthesis, respiration, and reproduction and the ecological processes of competition, grazing, and epibiosis. For all input combinations, the model delivers the monthly net growth rate near the bladder wrack's depth limit and the maximum depth of its vertical distribution. The use of data corresponding to conditions presently observed in the western Baltic Sea sets the year's maximum algal net growth rate in late spring and 2 minima in early spring and autumn. The depth limit of the wrack's distribution is set at $\sim 9 \mathrm{~m}$. Light and its absorption by phytoplankton represent by far the most important factors controlling the modeled net growth rate and depth penetration, with the role of epibiosis requiring further investigation. Lacking findings on population dynamics and biotic interactions restrict the generated model to an exploratory rather than a predictive tool.
\end{abstract}

KEY WORDS: Depth limit $\cdot$ Benthic ecology $\cdot$ Eutrophication $\cdot$ Ecological modeling $\cdot$ Bladder wrack - Biotic interactions $\cdot$ Fucus physiology

\section{INTRODUCTION}

The importance of coastal marine ecosystems as providers of indispensable services has been demonstrated e.g. by Costanza et al. (1998) and Worm et al. (2006), rendering a sound understanding of their natural function and their sensitivity to environmental change a top priority. Just like in many other ecosystems, primary production is a key process in coastal assemblages, supplying energy and matter to higher trophic levels. In the upper littoral zone of rocky shores in the Baltic Sea, this fundamental role is performed by phytobenthos along with phytoplankton and terrestrial inputs of organic matter. Among phytobenthic organisms, macroalgae hold a special place, since, acting as ecosystem engineers, they provide food, substratum, and refuge for many organisms. Especially members of the brown algal genus Fucus, the most important perennial, beltforming macroalgae on hard bottoms in the Baltic, allow the formation of the most species-rich community in the region and are generally considered as key elements of these ecosystems (Kautsky \& Kautsky 2000). The bladder wrack $F$. vesiculosus, with its wide distribution, high biomass, and high productivity is of particular importance. Changes in its distribution and abundance could have profound effects on the entire Baltic ecosystem, including coastal fisheries (Aneer et al. 1983, Haahtela 1984).

Fucus vesiculosus has undergone a significant reduction in occupied area and abundance, predominantly caused by a reduction in the maximum depth 
of its distribution during the second half of the last century (e.g. Kautsky et al. 1986, Vogt \& Schramm 1991, Eriksson et al. 1998). Although partial recovery has been observed at some sites in recent years (Nilsson et al. 2004), the general pattern of restricted depth penetration of $F$. vesiculosus in the Baltic Sea seems to persist (Torn et al. 2006). Among other factors, such as direct habitat destruction or increased grazing due to overfishing of the mesograzers' predators, eutrophication is considered to play the most prominent role in this change (Kautsky et al. 1986, Eriksson et al. 1998, Torn et al. 2006). The ways in which high nutrient levels can hinder the propagation and growth of $F$. vesiculosus are manifold, the most commonly reported being increased water turbidity (Kautsky et al. 1986), increased sedimentation rates (Eriksson \& Johansson 2003), increased grazing pressure (Kangas et al. 1982), direct inhibition of spore settlement and development (Bergström et al. 2003), increased epibiotic load (Wahl 1989), and increased competition with ephemeral algae and the blue mussel Mytilus edulis (Vogt \& Schramm 1991).

Considering all these possible effects of eutrophication on Fucus vesiculosus, one might be tempted to consider the question of its reduced depth penetration as answered. However, the fact that so many mechanisms and functional groups of organisms are involved, some of them, like epibionts, even having been credited with possibly positive effects on the alga (Wahl 2008), makes a reconsideration of this issue seem appropriate. Trends in the depth distribution of $F$. vesiculosus during the last 2 decades do not follow reported changes in nutrient or light levels (Torn et al. 2006), leading to some discussion about the biotic interactions around the alga and how they can modulate abiotic and biotic stress (e.g. Korpinen et al. 2007). Recent research has already yielded a sound delineation of the influence of individual and combined factors on the performance of Fucus plants (reviewed by Wahl et al. 2011). However, the complexity inherent in the system requires a step beyond these first levels of biological organization, incorporating them into a holistic image of coastal marine systems. Especially in the face of ongoing climate change, which will likely impose unprecedented stresses and often new combinations of them on many organisms, a synthesis of the existing knowledge on ecologically dominant species and their sensitivities to changing environmental conditions is expected to improve our understanding and - eventually - allow for more reliable predictions into the future (Harley et al. 2006).
It is in this context that we set out to build a numerical model synthesizing the current state of knowledge on abiotic and biotic interactions around Fucus vesiculosus. Our specific intention was to better understand observed changes in the maximum depth at which F. vesiculosus can thrive. Accordingly, the model was constructed with particular emphasis on identifying the depth level at which net growth of $F$. vesiculosus is just possible. The model does not attempt to predict the actual spread or biomass of the alga, although it may, in the future, be extended to allow incorporation into a more realistic representation of coastal marine systems.

\section{MATERIALS AND METHODS}

\section{Model description}

The model developed here is a deterministic numerical model, which seeks to capture the basic features controlling the vertical distribution of Fucus vesiculosus in the Baltic Sea. The primary output of the model is the algal net growth rate, computed for every month of the year on a discrete vertical grid. The depth of 0 net growth is then assumed to represent the alga's lower depth limit. Focusing on the maximum depth at which $F$. vesiculosus can grow, we concentrate on describing the environment that light-limited plants face at their depth limit, ignoring factors that might affect growth at much shallower depths. In the current study, we also focus on the factors that affect the growth of adult individuals, leaving recruitment processes aside despite their important role in population dynamics and the eventual fate of $F$. vesiculosus stands.

The basis of the model is a physiological model for carbon-specific net growth rate $\left(\mu_{c}\right)$ for light-limited macroalgae with a flat thallus (Markager \& SandJensen 1992, 1994):

$$
\mu_{c}{ }^{*}=\left(I \cdot \varphi_{g} \cdot A\right) / D-R_{m}-k \cdot\left(I \cdot \varphi_{g} \cdot A\right) / D
$$

Symbols and units are defined in Table 1 . The asterisk $\left({ }^{*}\right)$ notation indicates an interim definition of a variable, before all of its modeled components have been put into place (see Eq. 17 below). The term $\left(I \cdot \varphi_{g}\right.$ - A) $/ D$ represents the carbon-specific carbon gain per unit time, dependent on incident light $(I)$, the portion of $I$ being absorbed by the plant $(A)$, and the efficiency with which the plant utilizes $I$ for the production of biomass $\left(\varphi_{g}\right)$. Carbon losses include $R_{m}$, the carbonspecific maintenance respiration, and $k \cdot\left(I \cdot \varphi_{g} \cdot A\right) / D$. The latter represents the increase in respiration rate 
per unit increase in gross growth rate and corresponds to the respiration used to support cell growth.

The decline of light $(I)$ with depth $(z)$ is described by the Beer-Lambert relationship (Beer 1852):

$$
I=I_{0} \cdot \exp (-\varepsilon \cdot z)
$$

The extinction coefficient $(\varepsilon)$ is modeled as a sum of 2 constituents (e.g. Oschlies \& Garçon 1999):

$$
\varepsilon=\varepsilon_{0}+a \cdot C h l
$$

where $\varepsilon_{0}$ represents the year-round background light diminishing factors, which can be of great importance in coastal waters, while $(a \cdot C h l)$ accounts for the extinction coefficient's dependence on seasonal variations in chlorophyll a (chl a) concentration (Chl).

The photosynthetic rate of plants suffering from light limitation is insensitive to temperature variations within ranges expected for the Baltic Sea (Lüning 1990), while a combination of low nutrient requirements and nutrient storage ability minimizes nutrient control over Fucus vesiculosus growth (Pedersen \& Borum 1996). Thus, photosynthetic rates are considered sensitive to only one other factor in addition to light, namely salinity, possibly owing to the effect that its variation has on the algal cell structure (Nygard \& Dring 2008). Applying non-linear regression analysis in STATISTICA (StatSoft) on data of photosynthetic rate against salinity level (Bäck et al. 1992), a 2nd-order polynomial equation is obtained, which describes the relationship between gross quantum yield for growth $\left(\varphi_{g}\right)$ and salinity $(S)$ :

$$
\varphi_{g}^{*}=\varphi_{g 0}+b \cdot S-\mathrm{c} \cdot S^{2}
$$

The intercept value of this equation $\left(\varphi_{g 0}\right)$ also sets the lower limit for the values that gross quantum yield for growth can acquire within the range of expected salinity levels in the Baltic Sea (Bäck et al. 1992), resulting in the following equation for the gross quantum yield for growth:

$$
\varphi_{g}=\max \left(\varphi_{g}{ }^{*}, \varphi_{g 0}\right)
$$

The main factor controlling algal respiration rate is

\begin{tabular}{|c|c|c|c|c|c|}
\hline Symbol & Description & Units & Symbol & Description & Units \\
\hline$\mu_{c}$ & $\mathrm{C}$-specific net growth rate & $\mathrm{mmol} \mathrm{C} \mathrm{mol}^{-1}$ cell C d ${ }^{-1}$ & $L_{R}$ & Reproductive C-specific C loss rate & $\mathrm{mmol} \mathrm{C} \mathrm{mol}^{-1}$ cell C d $\mathrm{d}^{-1}$ \\
\hline$\mu_{c, \text { mean }}$ & Annual mean $\mu_{c}$ & $\mathrm{mmol} \mathrm{C} \mathrm{mol}^{-1}$ cell C d ${ }^{-1}$ & $R A$ & Reproductive allocation & Dimensionless \\
\hline$I$ & Incident irradiance & mol photon $\mathrm{m}^{-2} \mathrm{~d}^{-1}$ & $R E$ & Reproductive effort & Dimensionless \\
\hline$I_{0}$ & Sea surface irradiance & mol photon $\mathrm{m}^{-2} \mathrm{~d}^{-1}$ & $d$ & Division factor of light-limitited $R A$ & Dimensionless \\
\hline$\varphi_{g}$ & $\begin{array}{l}\text { Gross quantum yield } \\
\text { for growth }\end{array}$ & $\begin{array}{l}\text { mmol C mol} \\
\text { photon }\end{array}$ & $L_{G}$ & Grazing $\mathrm{C}$-specific $\mathrm{C}$ loss rate & $\mathrm{mmol} \mathrm{C} \mathrm{mol}^{-1}$ cell C d ${ }^{-1}$ \\
\hline$\varphi_{g 0}$ & Intercept of $\varphi_{g}-S$ equation & $\begin{array}{l}\text { mmol C } \mathrm{mol}^{-1} \text { absorbed } \\
\text { photon }\end{array}$ & $G R_{G}$ & Gammaridae grazing rate & mg DW Fucus ind. ${ }^{-1} \mathrm{~d}^{-1}$ \\
\hline$A$ & Fractional light absorption & Dimensionless & $G R_{I}$ & Idotea grazing rate & mg DW Fucus ind. ${ }^{-1} \mathrm{~d}^{-1}$ \\
\hline$D$ & Thallus area-specific carbon & mol $\mathrm{C} \mathrm{m}^{-2}$ thallus ( 1 side) & $e^{t}$ & Division factor of light-limited $G R$ & Dimensionless \\
\hline$R_{m}$ & $\begin{array}{l}\text { C-specific maintenance } \\
\text { respiration rate }\end{array}$ & $\mathrm{mmol} \mathrm{C} \mathrm{mol}^{-1}$ cell C d $\mathrm{d}^{-1}$ & $d_{G}$ & Gammaridae density & Ind. $100 \mathrm{~g}^{-1}$ DW Fucus \\
\hline$R_{m 0}$ & Reference $R_{m}$ value & $\mathrm{mmol} \mathrm{C} \mathrm{mol}^{-1}$ cell C d ${ }^{-1}$ & $d_{I}$ & Idotea density & Ind. $100 \mathrm{~g}^{-1}$ DW Fucus \\
\hline$k$ & $\begin{array}{l}\text { Slope of respiration-growth } \\
\text { equation }\end{array}$ & Dimensionless & $L_{E}$ & Epibiosis C-specific C loss rate & $\mathrm{mmol} \mathrm{C} \mathrm{mol}^{-1}$ cell C d $\mathrm{d}^{-1}$ \\
\hline$k_{0}$ & Reference $k$ value & Dimensionless & $E L$ & Epibiotic load & g DW epibiont $\mathrm{g}^{-1}$ DW Fucus \\
\hline$\varepsilon$ & Extinction coefficient & $\mathrm{m}^{-1}$ & $f$ & Slope of $L_{E}-E L$ equation & Dimensionless \\
\hline$\varepsilon_{0}$ & Background $\varepsilon$ constituent & $\mathrm{m}^{-1}$ & $E p L$ & Epiphytic load & g DW epiphyte $g^{-1}$ DW Fucus \\
\hline$z$ & Depth & $\mathrm{m}$ & $E p L_{0}$ & Intercept of $E p L-D I N$ equation & g DW epiphyte $g^{-1}$ DW Fucus \\
\hline a & Slope of $\varepsilon-C h l$ equation & Dimensionless & $g$ & Slope of $E p L-D I N$ equation & Dimensionless \\
\hline Chl & Chlorophyll a concentration & $\mathrm{g} \mathrm{chl} a \mathrm{~m}^{-3}$ & DIN & Dissolved inorganic nitrogen conc. & $\mu g \mathrm{~N}^{-1}$ \\
\hline$S$ & Salinity & psu & $D I N_{m}$ & $D I N$ mean over the year & $\mu \mathrm{g} \mathrm{N} l^{-1}$ \\
\hline$b$ & $\begin{array}{l}\text { 2nd term coefficient of } \varphi_{g}-\mathrm{S} \\
\text { equation }\end{array}$ & Dimensionless & $D I N_{\text {ref }}$ & Reference $D I N$ value & $\mu g \mathrm{~N}^{-1}$ \\
\hline C & $\begin{array}{l}\text { 3rd term coefficient of } \varphi_{g}-\mathrm{S} \\
\text { equation }\end{array}$ & Dimensionless & $h$ & Division factor of light-limited $E L$ & Dimensionless \\
\hline$T$ & Temperature & ${ }^{\circ} \mathrm{C}$ & $P_{G}$ & Grazing probability & Dimensionless \\
\hline$T_{\text {ref, } R}$ & Respiration reference $T$ value & ${ }^{\circ} \mathrm{C}$ & $P_{G 0}$ & Intercept of $P_{G}-E L$ equation & Dimensionless \\
\hline$T_{r e f, G}$ & Grazing reference $T$ value & ${ }^{\circ} \mathrm{C}$ & $i$ & Slope of $P_{G}-E L$ equation & Dimensionless \\
\hline$T_{r e f, E}$ & Epibiosis reference $T$ value & ${ }^{\circ} \mathrm{C}$ & $j$ & Slope of $d_{G}-D I N_{m}$ equation & Dimensionless \\
\hline$Q_{10}$ & Temperature coefficient & Dimensionless & $k$ & Slope of $d_{I}-D I N_{m}$ equation & Dimensionless \\
\hline
\end{tabular}
temperature (Lüning 1990), this relationship being most commonly described by the largely empirical

Table 1. Symbols, descriptions and units of variables and parameters used in the model. DW: dry weight 
$Q_{10}$ formulation (van't Hoff 1884). This formulation is applied to both terms constituting respiration losses:

$$
\begin{aligned}
R_{m} & =R_{m 0} \cdot \exp \left\{\left[\left(T-T_{\mathrm{ref}, R}\right) / 10\right] \cdot \ln \left(Q_{10}\right)\right\} \\
k & =k_{0} \cdot \exp \left\{\left[\left(T-T_{\mathrm{ref}, R}\right) / 10\right] \cdot \ln \left(Q_{10}\right)\right\}
\end{aligned}
$$

The temperature coefficient $Q_{10}$ is the factor of respiration increase for every $10^{\circ} \mathrm{C}$ increase in temperature $(T)$, while $T_{\text {ref, } R}$ represents the temperature at which $R_{m}$ and $k$ equal their reference values, $R_{m 0}$ and $k_{0}$, respectively.

Reproduction also imposes carbon losses on the algae, on account of biomass produced by the vegetative parts of the plant, allocated to receptacles during their development (reproductive allocation, $R A$ ) and lost after their abscission. Development of the reproductive tissue takes place over a period of $1 \mathrm{mo}$ (Berger et al. 2001), and the amount of carbon allocated to it during that time relative to the plant's vegetative tissue carbon equals the quotient $R A /(1-R A)$. Reproductive allocation alone is not sufficient for the assessment of the cost for the plant, owing to the fact that reproductive tissue itself contributes with its own photosynthetic production (Brenchley et al. 1996). The proportion of reproductive carbon requirements contributed by receptacle photosynthesis is termed reproductive effort ( $R E$; Brenchley et al. 1996), and taking it into consideration yields the formulation of reproduction-related carbon-specific carbon loss $\left(L_{R}\right)$ during the month of receptacle development. Finally, $R A$ is divided by the parameter $d$, to account for stress-induced reduction of $R A$ (Dethier et al. 2005):

$$
L_{R}=[(1-R E) \cdot(R A / d)] /[1-(R A / d)]
$$

Herbivory has been credited with both positive (Jormalainen et al. 2003) and negative (Engkvist et al. 2000) effects on Fucus vesiculosus growth. However, costs related to the loss of algal tissue seem to dominate this interaction (Wahl et al. 2011). This is particularly so near the plant's depth limit, where the scarcity of epiphytes and the dominance of epibiotic animals (Rohde et al. 2008) minimize the grazers' potential to effectively remove epibiotic load. The most abundant grazers found among $F$. vesiculosusassociated mesofauna include Gammaridae amphipods and members of the isopods of the genus Idotea (Anders \& Möller 1983). Other important mesograzers, like the gastropod Littorina littorea, feed primarily on germlings, while adult sporophytes escape herbivore control by virtue of a size-related refuge (Lubchenco 1983). The carbon loss due to grazing equals the sum of the products of the grazing rates of individual Gammaridae and Idotea $\left(G R_{G}, G R_{I}\right)$ and their density levels for every month of the year $\left(d_{G \prime}\right.$
$\left.d_{I}\right)$. After the $Q_{10}$ formulation has been added, accounting for the dependence of metabolic rates and thus grazing rates of the animals on temperature, grazing rates are divided by the parameter $e_{\text {, ac- }}$ counting for the effect of light limitation on the plant's palatability, possibly due to reduced production of grazer-attracting compounds (Weinberger et al. 2011). Eventually, the equation for grazingrelated carbon-specific carbon loss per unit time $\left(L_{G}\right)$ is formulated as follows:

$$
\begin{aligned}
L_{G}{ }^{*}= & {\left[\left(G R_{G} \cdot d_{G}+G R_{I} \cdot d_{I}\right) / e\right] \cdot } \\
& \exp \left\{\left[\left(T-T_{r e f, G}\right) / 10\right] \cdot \ln \left(Q_{10}\right)\right\}
\end{aligned}
$$

A wide variety of ways in which algal growth can be affected by epibiosis have been proposed, owing to the ubiquitous presence of epibionts in sea water and the crucial position they have at the functional plant-environment interface (Wahl 1989). Shading of the basibiont has been pointed out as the most general effect, since physiologically different epibiont species have been found to have similar impacts on algal growth (Rohde et al. 2008). This finding also allows for data on the effect of epiphytes on Fucus vesiculosus growth to be used in cases (like that of plants near their depth limit) where the epibiotic load consists mainly of animals. Accordingly, the application of linear regression analysis (STATISTICA, StatSoft) on data of growth rate against epiphytic load (Worm \& Sommer 2000) yields the following linear approximation, describing the relationship between epibiotic load $(E L)$ and epibiosis-related carbonspecific carbon loss per unit time $\left(L_{E}\right)$ :

$$
L_{E}=f \cdot E L
$$

Variations of epibiotic load on Fucus vesiculosus near its depth limit, consisting primarily of annelid worms (Rohde et al. 2008), are considered to be linked with the $Q_{10}$ formulation of van't Hoff (1884), since the abundance of these meiofaunal organisms has been found to follow the seasonal pattern of sea water temperature (Witte \& Zijlstra 1984). In order for a reference value of epibiotic load to be extracted, linear regression analysis was performed with STATISTICA (StatSoft) on data of epiphytic load ( $E p L)$ against dissolved inorganic nitrogen concentration (DIN) (Jormalainen et al. 2003), producing the following equation:

$$
E p L=E p L_{0}+g \cdot D I N
$$

A reference $D I N$ value $\left(D I N_{\text {ref }}\right)$ is assumed, and the resulting epiphytic load is divided by the parameter $h$ to account for decreased epibiotic load on plants near their depth limit, associated with changes 
in the composition of the fouling community (Rohde et al. 2008). Assuming that seasonal variations in this load can be largely explained by temperature, the product is incorporated into the $Q_{10}$ formulation, to generate the equation determining the amount of seasonally varying epibiotic load (EL) on Fucus vesiculosus:

$$
\begin{aligned}
E L= & {\left[\left(E p L_{0}+g \cdot D I N_{r e f}\right) / h\right] \cdot } \\
& \exp \left\{\left[\left(T-T_{r e f, E}\right) / 10\right] \cdot \ln \left(Q_{10}\right)\right\}
\end{aligned}
$$

Epibiosis has another well established effect on Fucus vesiculosus growth. The presence of epibionts has been found to significantly decrease the probability of a plant being grazed by the isopod Idotea (Jormalainen et al. 2008). Under the simplifying assumption that the probability of grazing $\left(P_{G}\right)$ and the epibiotic load $(E L)$ are connected through a linear relationship, the following equation describing this interaction is produced:

$$
P_{G}=P_{G 0}-i \cdot E L
$$

Further assuming that the probability of grazing is independent of the individual grazer's grazing rates, a more reasonable representation of the realized grazing loss can be obtained by multiplying $L_{G}{ }^{*}$ (Eq. 9) by the above grazing probability.

Grazing losses of Fucus vesiculosus are also affected by nutrient levels and their indirect effect on herbivore density through control of ephemeral macroalgae (Bokn et al. 2002). Based on data from this study and using the mean DIN value over the year $\left(D I N_{m}\right)$ as a measure of nutrient level, the formulations describing Gammaridae and Idotea densities are respectively converted into:

$$
\begin{aligned}
d_{G}^{*} & =d_{G}+j \cdot D I N_{m} \\
d_{I}^{*} & =d_{I}+k \cdot D I N_{m}
\end{aligned}
$$

yielding the following expression for total loss by grazing:

$$
\begin{aligned}
L_{G}= & P_{G} \cdot\left[\left(G R_{G} \cdot d_{G}{ }^{*}+G R_{I} \cdot d_{I}^{*}\right) / e\right] \\
& \exp \left\{\left[\left(T-T_{r e f, G}\right) / 10\right] \cdot \ln \left(Q_{10}\right)\right\}
\end{aligned}
$$

In order for the changes in herbivore density that result from the consumption of ephemeral macroalgae not to be exclusively translated into changes in Fucus vesiculosus consumption, the grazing rates used as input $\left(G R_{G}\right.$ and $\left.G R_{I}\right)$ should be derived from experiments where grazers are offered both $F$. vesiculosus and ephemeral macroalgae.

An overview of all the processes described above is given in Fig. 1. According to our model, the carbonspecific net growth rate of Fucus vesiculosus $\left(\mu_{c}\right)$ is given by the following formulation, whose right- hand side terms are derived from Eqs. (1), (8), (10), and (16), respectively:

$$
\mu_{c}=\mu_{c}^{*}-L_{R}-L_{E}-L_{G}
$$

Once $\mu_{c}$ has been computed at every depth level of the model and for every month of the year, the alga's depth limit $\left(z_{L}\right)$ is computed as the greatest depth at which the annual mean carbon-specific net growth rate $\left(\mu_{c, \text { mean }}\right)$ is $>0$. This assumes that negative growth rates can be sustained over some periods of the year, provided that positive growth rates during the rest of the time can make up for the loss. This assumption is based on the plant's ability to store energy in the form of mannitol or laminaran for use in periods of limited resources (Lehvo et al. 2001).

\section{Model solution}

The above described model (Eq. 17) was arranged in the form of a matrix with rows representing the number of months in a year and columns representing the number of depth intervals. The elements of the matrix represent values of Fucus vesiculosus net growth rate $\left(\mu_{c}\right)$ corresponding to a particular month and depth level. All required computations were carried out numerically with the computing software MATLAB R2009a (The MathWorks). The time constituent of the model, which is represented by the 12 rows of the matrix, is incorporated through the struc-

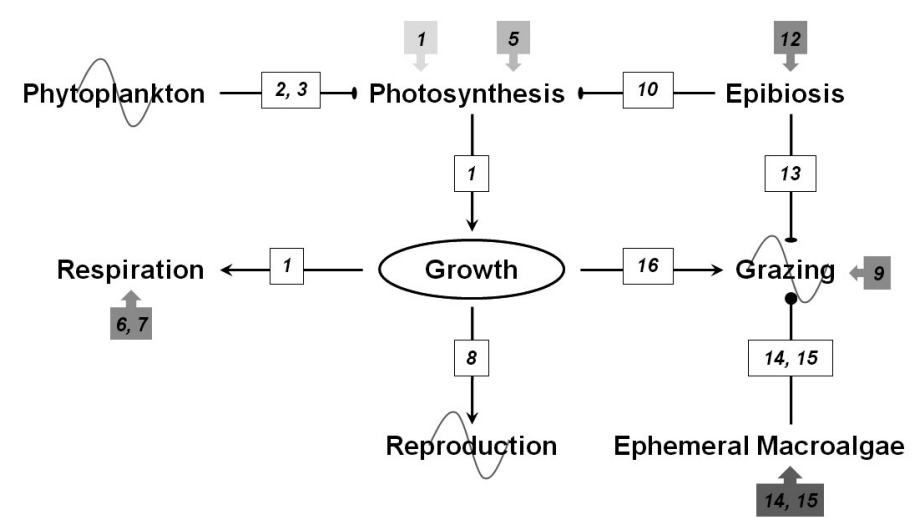

Fig. 1. Diagram of the interactions comprising the model. Pointed, flat-end or round-end arrows represent carbon fluxes, process diminutions, or amplifications, respectively. Numbers correspond to equations describing the respective interactions (see 'Materials and methods'). Sinusoids indicate predefined seasonal variation. Grey boxes represent external variables influencing model processes (from light to dark, 4 grey shades correspond to incident irradiance, salinity, temperature, and dissolved inorganic nitrogen concentration, respectively) 
ture of seasonally varying external variables and parameters, namely $S, T, C h l, R A, d_{G r}$ and $d_{I}$. These model components, constituting $12 \times 1$ column vectors, are introduced into Eqs. (3), (5), (6), (7), (8), (10), and (16), always taking conformity of units into consideration, to respectively produce $12 \times 1$ column vectors of $\varepsilon_{1} \varphi_{g}, R_{m}, k, L_{R}, L_{E}$, and $L_{G}$ the elements of which represent the monthly variation of the corresponding state variables.

The depth constituent is introduced into Eq. (2) as a $1 \times 5001$ row vector $z$, representing a depth gradient from 0 to $50 \mathrm{~m}$, divided into intervals of $0.01 \mathrm{~m}$. The selected depth range and resolution serve the goal of allowing the full exploration of the model's behavior, especially during its formation, even if they are not biologically relevant. Within this equation, the $\varepsilon \times z$ matrix multiplication yields a $12 \times 5001$ matrix, which is further multiplied by monthly-mean values of surface irradiance $\left(I_{0}\right)$, to produce a $12 \times 5001$ matrix of irradiance $(I)$ values across time and depth. All other external variables (temperature, salinity, nutrients, and chl a concentration) are assumed to be depth independent in the usually well-mixed near-surface waters. For each month and depth, the monthly carbon-specific net growth rate is computed as: $\mu_{c}=\left[(1-k) \cdot \varphi_{g} \cdot I \cdot A\right] / D-R_{m}-L_{R}-L_{E}-L_{G}$

Finally, Fucus vesiculosus $z_{L}$ is derived from the calculation of $\mu_{c, \text { mean }}$ and, since the latter is a monotonically decreasing function of depth, determination of the greatest depth where it is $>0$.

The model input includes constant parameters $\left(A_{\text {, }}\right.$ $D, \varepsilon_{0}, a, \varphi_{g 0}, b, \quad c, R_{m 0}, k_{0}, T_{\text {ref }, R}, Q_{10}, R E, d, G R_{G r}$ $\left.G R_{I}, e, T_{\text {ref,Gr }} f, E p L_{0}, g, D I N_{\text {reft }} h, T_{\text {ref,Er }} P_{G 0}, i, j, k\right)$, seasonally varying parameters $\left(R A, d_{G}, d_{I}\right)$, and external variables $\left(I_{0}, C h l, S, T, D I N\right)$. The values assigned to these parameters and the sources from which they have been drawn can be found in Tables 2 \& 3. An effort was made to use data derived from studies on Baltic Fucus vesiculosus. Due to the occasional lack of data on this particular species, we also used data derived from studies on the closely related $F$. serratus. The choices concerning the values of the external variables were made in an attempt to reproduce the underwater environment of coastal waters in the western Baltic Sea $\left(55^{\circ} \mathrm{N}, 10^{\circ} \mathrm{E}\right)$. The highly variable environmental conditions that plants occupying this habitat encounter can be represented only in an averaged sense by the current model. A more realistic treat-

Table 2. Model input: constant parameters and references. DW: dry weight

\begin{tabular}{|c|c|c|c|}
\hline Parameter & Value & Units & Source \\
\hline$\varphi_{g 0}$ & 98 & mmol C mol ${ }^{-1}$ absorbed photon & Markager \& Sand-Jensen (1992) \\
\hline$A$ & 0.74 & Dimensionless & Nygard \& Dring (2008) \\
\hline$D$ & 2.46 & mol C m${ }^{-2}$ thallus ( 1 side) & Markager \& Sand-Jensen (1992) \\
\hline$R_{m 0}$ & 2.7 & mmol C mol ${ }^{-1}$ cell $\mathrm{C} \mathrm{d}^{-1}$ & Markager \& Sand-Jensen (1992) \\
\hline$k_{0}$ & 0.06 & Dimensionless & Markager \& Sand-Jensen (1992) \\
\hline$\varepsilon_{0}$ & 0.4 & $\mathrm{~m}^{-1}$ & Rohde et al. (2008) \\
\hline$a$ & 16 & Dimensionless & M. Pahlow (pers. comm.) \\
\hline$b$ & 9 & Dimensionless & Bäck et al. (1992) \\
\hline C & 0.75 & Dimensionless & Bäck et al. (1992) \\
\hline$T_{r e f, R}$ & 7 & ${ }^{\circ} \mathrm{C}$ & Markager \& Sand-Jensen (1992) \\
\hline$T_{r e f, G}$ & 15 & ${ }^{\circ} \mathrm{C}$ & Goecker \& Kåll (2003) \\
\hline$T_{r e f, E}$ & 11.5 & ${ }^{\circ} \mathrm{C}$ & Rohde et al. (2008) \\
\hline$Q_{10}$ & 2 & Dimensionless & Goldman \& Carpenter (1974) \\
\hline$R E$ & 0.2 & Dimensionless & Brenchley et al. (1996) \\
\hline$d$ & 1.5 & Dimensionless & Dethier et al. (2005) \\
\hline$G R_{G}$ & 0.15 & mg DW Fucus ind. ${ }^{-1} \mathrm{~d}^{-1}$ & Goecker \& Kåll (2003) \\
\hline$G R_{I}$ & 0.89 & mg DW Fucus ind..$^{-1} \mathrm{~d}^{-1}$ & Goecker \& Kåll (2003) \\
\hline e & 4 & Dimensionless & Weinberger et al. (2011) \\
\hline$f$ & 150 & Dimensionless & Worm \& Sommer (2000) \\
\hline$E p L_{0}$ & 0.02 & g DW epiphyte $\mathrm{g}^{-1} \mathrm{DW}$ Fucus & Jormalainen et al. (2003) \\
\hline$g$ & 0.001 & Dimensionless & Jormalainen et al. (2003) \\
\hline$D I N_{\text {ref }}$ & 21 & $\mu g \mathrm{~N}^{-1}$ & Rohde et al. (2008) \\
\hline$h$ & 2.25 & Dimensionless & Rohde et al. (2008) \\
\hline$P_{G 0}$ & 0.56 & Dimensionless & Jormalainen et al. (2008) \\
\hline$i$ & 6.5 & Dimensionless & Jormalainen et al. (2008) \\
\hline$j$ & 0.25 & Dimensionless & Bokn et al. (2002) \\
\hline$k$ & 0.25 & Dimensionless & Bokn et al. (2002) \\
\hline
\end{tabular}


Table 3. Model input: seasonally varying parameters or external variables. RA values from Berger et al. (2001), $d_{G}$ and $d_{I}$ from Anders \& Möller (1983), $I_{0}$ from Lund-Hansen \& Sørensen (2009), and the remaining parameter values from Zervoudaki et al. (2009). DW: dry weight

\begin{tabular}{|c|c|c|c|c|c|c|c|c|c|c|c|c|c|}
\hline & Jan & Feb & Mar & Apr & May & Jun & Jul & Aug & Sep & Oct & Nov & Dec & Units \\
\hline$R A$ & 0 & 0 & 0 & 0.23 & 0 & 0 & 0 & 0 & 0 & 0 & 0 & 0 & Dimensionless \\
\hline$d_{G}$ & 15.3 & 1.2 & 1.2 & 46.9 & 46.9 & 1523.9 & 2540.9 & 906.5 & 144.7 & 44.1 & 35.8 & 24.5 & ind. $100 \mathrm{~g}^{-1} \mathrm{DW}$ Fucus \\
\hline$d_{I}$ & 0 & 0 & 0 & 1.2 & 1.2 & 135.5 & 234.7 & 210.3 & 59.8 & 10.2 & 0.4 & 0 & ind. $100 \mathrm{~g}^{-1} \mathrm{DW}$ Fucus \\
\hline$I_{0}$ & 12 & 14 & 20 & 27 & 37 & 43 & 46 & 44 & 38 & 21 & 13 & 12 & mol photon $\mathrm{m}^{-2} \mathrm{~d}^{-1}$ \\
\hline Chl & 0.005 & 0.0055 & 0.0225 & 0.0065 & 0.007 & 0.008 & 0.0075 & 0.007 & 0.0125 & 0.0105 & 0.0085 & 0.003 & $\mathrm{~g} \mathrm{chl} \mathrm{a} \mathrm{m}^{-3}$ \\
\hline$S$ & 17 & 19 & 17 & 11 & 6 & 4 & 7 & 9 & 10 & 11 & 15 & 16 & $\mathrm{psu}$ \\
\hline$T$ & 4 & 3.5 & 3.5 & 6 & 10.5 & 13 & 16 & 17 & 15.5 & 11.5 & 8 & 5 & ${ }^{\circ} \mathrm{C}$ \\
\hline$D I N$ & 161 & 161 & 49 & 28 & 21 & 7 & 14 & 7 & 7 & 21 & 49 & 105 & $\mu g \mathrm{~N}^{-1}$ \\
\hline
\end{tabular}

Table 4. Modeled depth limit $\left(z_{L}\right)$ corresponding to the gradual removal of model components. w/o: without the effect of

\begin{tabular}{|lr|}
\hline Model description & $z_{L}(\mathrm{~m})$ \\
\hline (1): Standard model & 9.28 \\
(2): (1) w/o ephemeral macroalgae on grazing & 9.28 \\
(3): (1) w/o epibiosis on grazing & 9.22 \\
(4): (1) w/o external biotic factors & 9.23 \\
(5): (4) w/o phytoplankton on growth & 12.13 \\
(6): (4) w/o grazing on growth & 9.32 \\
(7): (4) w/o epibiosis on growth & 10.15 \\
(8): (4) w/o external biotic factors on growth & 13.52 \\
(9): (8) w/o maintenance respiration on growth & 19.13 \\
(10): (8) w/o reproduction on growth & 13.8 \\
\hline
\end{tabular}

ment is the scope of future work that will have to account for regional and shorter-term variations.

\section{Sensitivity analysis}

In order to assess the different roles played by different processes and their interactions in the system, the model's components are gradually removed and the impact on the predicted maximum depth is evaluated. The order in which this is done is shown in Table 4. Even if certain steps in this process do not make much sense from a natural point of view, they are still studied, in order to put every element of this mechanistic model into perspective.

The values of the input parameters used for the solution of the model were drawn from physiological and ecological studies, with no calibration being performed. It is useful, nevertheless, for further applications and the evaluation of the validity of the model to be aware of the sensitivity of its behavior against variation in these parameters. For this purpose, a percentage of the input parameters' values is subtracted and added to them in turn and changes in modeled depth limit $\left(z_{L}\right)$ are monitored. The percentage by which individual parameters are varied in this sensitivity analysis increases from parameters representing physical ( $\pm 10 \%: A, D, \varepsilon_{0}$, a) to those representing physiological ( $\left.\pm 20 \%: \varphi_{g 0}, b, c, R_{m 0}, k_{0}, Q_{10}, R E, d, R A\right)$ and ecological interactions $\left( \pm 30 \%: G R_{G}, G R_{I}, e, f\right.$, $\left.E p L_{0}, g, h, P_{G 0}, i, j, k, d_{G}, d_{I}\right)$, corresponding to an increased complexity and lower predictability of the respective processes involved.

The external variables included in the model are the primary source of monthly variation of plant net growth rate $\left(\mu_{c}\right)$, but they do not all exert the same extent of control over the behavior of the model. Aiming to estimate the degree to which such seasonally varying components affect the system, we also performed sensitivity analysis with respect to changes in the external variables $\left(I_{0}, C h l, S, T, D I N\right)$. Thus, the amount of $1 \mathrm{SD}$ among measurements performed in different years is subtracted and added to each of the monthly input parameters, and the effect on the model's output is assessed. The values and standard deviations of all external variables, except for $I_{0}$ (Lund-Hansen \& Sørensen 2009), stem from the same monitoring effort (Zervoudaki et al. 2009) and are therefore based on similar sampling procedures.

\section{RESULTS}

\section{Model solution}

For the input parameters given in Tables $2 \& 3$ and derived from literature values as described in the previous section, the maximum depth for positive yearly mean net growth rate $\left(\mu_{c, \text { mean }}\right)$ of Fucus vesiculosus in the western Baltic Sea is predicted as $z_{L}=$ $9.28 \mathrm{~m}$. An overview of net growth rate $\left(\mu_{c}\right)$ variations during the annual cycle at this depth is given in 


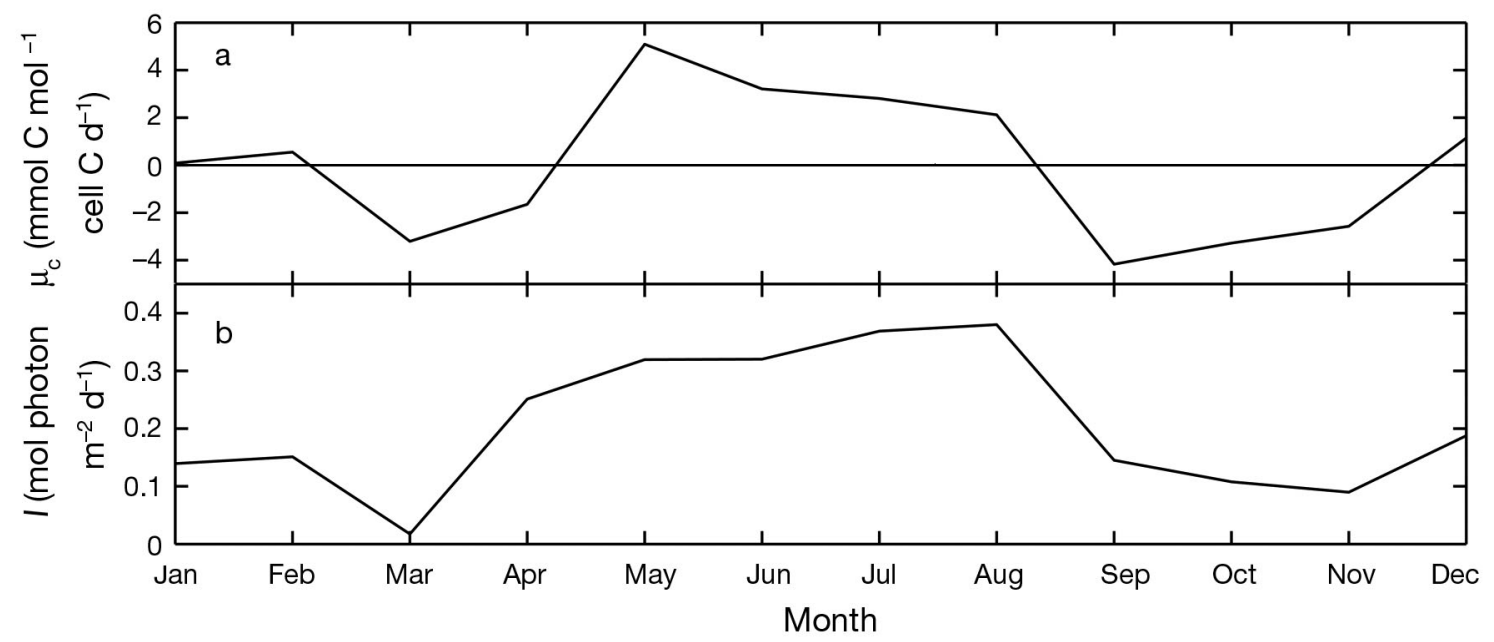

Fig. 2. Modeled year-round (a) net growth rate $\left(\mu_{c}\right)$ and (b) incident irradiance $(I)$ at the depth limit of $9.28 \mathrm{~m}$ for the standard parameters (Tables $2 \& 3$ )

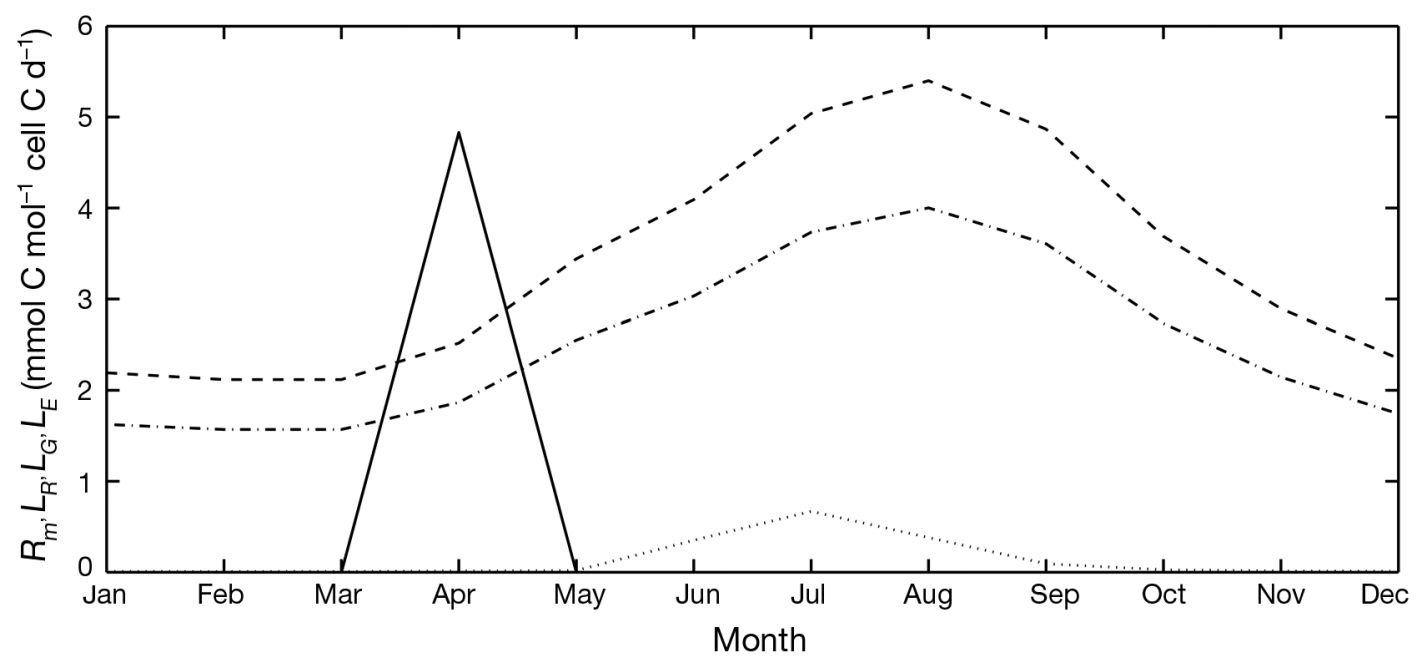

Fig. 3. Modeled year-round maintenance respiration $\left(R_{m}\right.$ : dash), reproduction-related carbon losses $\left(L_{R}\right.$ : solid), grazing-related carbon losses ( $L_{G}:$ dot), and epibiosis-related carbon losses ( $L_{E}:$ dash-dot) for the standard parameters (Tables 2 \& 3 )

Fig. 2a. Maximum values of $\mu_{c}$ are simulated for the period between May and August, with a peak in May and a decline thereafter. Winter months also reveal small positive values of $\mu_{c}$, whereas $\mu_{c}$ becomes negative during the first 2 mo of spring and throughout autumn, with lowest values simulated for September. Resembling this pattern, but with distinct differences, is the seasonal variation of irradiance (I) through the year at the same depth (Fig. 2b). Highest values are observed in late spring and summer, with the peak occurring in August, following a minimum in March.

Potential factors that can explain differences in the seasonal patterns of $\mu_{c}$ and $I$ include carbon losses related to maintenance respiration $\left(R_{m}\right)$, reproduction $\left(L_{R}\right)$, grazing $\left(L_{G}\right)$, and epibiosis $\left(L_{E}\right)$. Their seasonal variation is depicted in Fig. 3. $R_{m}$ and $L_{E}$, both being controlled by temperature, follow a bell-shaped pattern, with a peak in August and a plateau of minimum values throughout winter months and March. Both appear to exert the most significant overall pressure on $\mu_{c}\left(R_{m}\right.$ surpassing $\left.L_{E}\right)$, as they are effective throughout the year. The influence of $L_{R}$ is restricted to April, the month of receptacle development. $L_{G}$ on the other hand appears to have a relatively minor impact, virtually restricted to the summer months, with a peak observed in July. 


\section{Sensitivity analysis}

The result of the gradual removal of the processes that affect net growth rate of Fucus vesiculosus on modeled $z_{L}$ is given in Table 4. Omitting the control of epibiosis over grazing leads to a slight reduction in predicted depth penetration of F. vesiculosus (by $0.06 \mathrm{~m}$ ), while the omission of the effect of ephemeral macroalgal growth on grazing has virtually no effect. The consequence that both effects on grazing have on $z_{L}$ is therefore small compared to the effects of other processes considered by the model. The most prominent effect among external biotic factors is that of phytoplankton on irradiance, which is translated into a $2.9 \mathrm{~m}$ reduction in $z_{L}$. Irradiance levels at $z_{L}$ modeled without taking phytoplankton into account (Fig. 4a), illustrate how phytoplankton alters light quantity available to the plant, particularly at times of high phytoplankton concentration during early spring and autumn. The second largest external effect on $z_{L}$ comes from epibiosis, with its removal from the model equations resulting in an increase of $z_{L}$ by $\sim \mathrm{m}$ and an increase in $\mu_{c^{\prime}}$ which is particularly obvious during the epibiosis peak in late summer
(Fig. 4b). In comparison, the effect of grazing appears to be much smaller. The combined effect of all external biotic factors (omission leads to $4.29 \mathrm{~m}$ increase in $z_{L}$ ) by far exceeds in absolute numbers the combined effect of the interactions among them, i.e. the effect of epibiosis and ephemeral macroalgae on grazing (omission leads to $0.05 \mathrm{~m}$ reduction in $Z_{L}$ ). The removal of all external biotic factors and interactions among them results in a more evenly bell-shaped course of $\mu_{C}$ at $z_{L}$ (with the exception of a reproduction-induced steep drop in April), reaching its peak in early summer (Fig. 4c). Internal biotic factors are credited with even greater importance, with maintenance respiration appearing responsible for a $Z_{L}$ reduction of $5.61 \mathrm{~m}$, while the reproduction-induced $z_{L}$ reduction $(0.28 \mathrm{~m})$ turns out to be much smaller according to our model. The removal of both maintenance respiration and reproduction not only alters the form of the year-round course of $\mu_{c}$, but also shifts its peak into July (Fig. 4d), such that it closely follows the course of $I$ in the absence of phytoplankton (Fig. 4a).

The effect of varying individual parameter values on modeled $z_{L}$ is demonstrated in Table 5. Largest
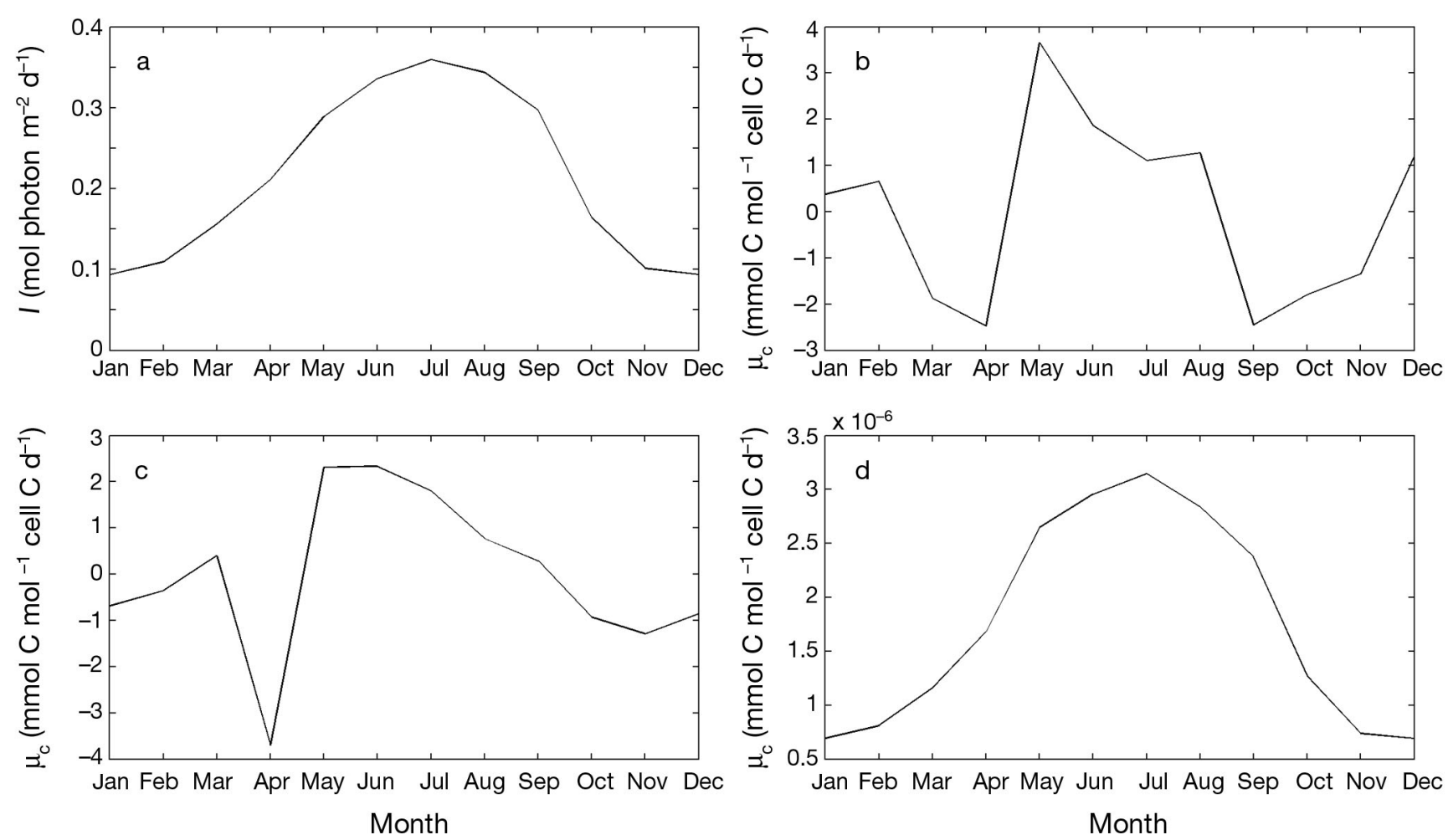

Fig. 4. Year-round modeling of state variables at the depth limit, in the absence of different factors (a) incident irradiance ( $I$ ) in absence of phytoplankton (Model 5 in Table 4), (b) net growth rate $\left(\mu_{c}\right)$ in the absence of epibiosis (Model 7 in Table 4), (c) $\mu_{c}$ in the absence of external biotic factors (Model 8 in Table 4) and (d) $\mu_{c}$ at depth of $50 \mathrm{~m}$ (lower limit of depth range, since no depth limit can be reached) in the absence of external biotic factors, maintenance respiration, and reproduction 
Table 5. Change of modeled depth limit $\left(\Delta z_{L}\right)$ corresponding to variations in input parameters by (a) $\pm 10 \%$, (b) $\pm 20 \%$ and (c) $\pm 30 \%$. The sign of $\Delta z_{L}$ values indicates the sign of the relationship between input parameters and modeled $z_{L}$. Input parameters are described in Table 1

\begin{tabular}{|c|c|c|}
\hline Variation & Parameter & $\Delta z_{L}(\mathrm{~m})$ \\
\hline \multirow[t]{4}{*}{ a) $\pm 10 \%$} & $A$ & 0.39 \\
\hline & $D$ & -0.39 \\
\hline & $\varepsilon_{0}$ & -1.45 \\
\hline & $a$ & -0.42 \\
\hline \multirow[t]{9}{*}{ b) $\pm 20 \%$} & $\varphi_{g 0}$ & 0.68 \\
\hline & $R_{m 0}$ & -0.41 \\
\hline & $k_{0}$ & -0.07 \\
\hline & $b$ & 0.32 \\
\hline & $C$ & -0.23 \\
\hline & $Q_{10}$ & -0.19 \\
\hline & $R E$ & 0.01 \\
\hline & $d$ & 0.06 \\
\hline & $R A$ & -0.06 \\
\hline \multirow[t]{13}{*}{ c) $\pm 30 \%$} & $G R_{G}$ & -0.02 \\
\hline & $G R_{I}$ & -0.01 \\
\hline & $e$ & 0.03 \\
\hline & $f$ & -0.46 \\
\hline & $E p L_{0}$ & -0.22 \\
\hline & $g$ & -0.23 \\
\hline & $h$ & 0.48 \\
\hline & $P_{G 0}$ & -0.03 \\
\hline & $i$ & 0.01 \\
\hline & $j$ & 0 \\
\hline & $k$ & 0 \\
\hline & $d_{G}$ & -0.01 \\
\hline & $d_{I}$ & -0.01 \\
\hline
\end{tabular}

sensitivities are observed in response to $\pm 10 \%$ variations of the background extinction coefficient $\left(\varepsilon_{0}\right.$, $\left.\Delta z_{L}=-1.45 \mathrm{~m}\right)$ and $\pm 20 \%$ variations of the gross quantum yield for growth $\left(\varphi_{g 0}, \Delta z_{L}=0.68 \mathrm{~m}\right)$. Variations by $\pm 30 \%$ of the values of the slope of the epibiosis loss versus epibiotic load relation $(f)$ and the division factor of light-limited epibiotic load $(h)$ result in $z_{L}$ changes of almost $0.5 \mathrm{~m}$, while changes of other parameters induce much smaller changes in modeled $Z_{L}$ values. The way the modeled depth limit varies in response to variations in the external variables is demonstrated in Table 6. Changes in DIN levels appear to have negligible impact on modeled $z_{L}$ values. Salinity $(S)$ and temperature $(T)$ follow, with variations in their values resulting in slightly greater but still essentially negligible effects on the model's outcome. Surface irradiance $\left(I_{0}\right)$ and chl a concentration $(\mathrm{Chl})$ are the environmental parameters whose control over the model's behavior is strongest. An increase in $I_{0}$ by values typical of recently observed interannual variability results in an overall increase of modeled $z_{L}$ by $0.73 \mathrm{~m}$, while the model appears
Table 6. Change of modeled depth limit $\left(\Delta z_{L}\right)$ corresponding to variations in input external variables by $\pm 1 \mathrm{SD}$. Value for $I_{0}$ from Lund-Hansen \& Sørensen (2009); all others from Zervoudaki et al. (2009). The sign of $\Delta z_{L}$ values indicates the sign of the relationship between input external variables and modeled $z_{L}$. Input parameters are described in Table 1

\begin{tabular}{|lcc|}
\hline External variable & $1 \mathrm{SD}$ & $\Delta z_{L}(\mathrm{~m})$ \\
\hline$T$ & $\pm 0.2^{\circ} \mathrm{C}$ & -0.06 \\
$S$ & \pm 0.6 & -0.04 \\
$I_{0}$ & $\pm 5 \mathrm{~mol} \mathrm{photon} \mathrm{m}^{-2} \mathrm{~d}^{-1}$ & 0.73 \\
$D I N$ & $\pm 7 \mathrm{\mu} \mathrm{N} \mathrm{l}^{-1}$ & 0 \\
$C h l$ & $\pm 0.002 \mathrm{~g} \mathrm{chl} \mathrm{a} \mathrm{m}^{-3}$ & -1.15 \\
& & \\
\hline
\end{tabular}

most sensitive to changes in $C h l$ levels, responding toan increase that corresponds to typical interannual variability with a $z_{L}$ reduction of $1.15 \mathrm{~m}$. The responses of modeled $z_{L}$ to fluctuations of input parameters and external variables within their preassigned ranges are more or less symmetrical around the standard value.

\section{DISCUSSION}

The input parameters used for the computation of the maximum depth of Fucus vesiculosus correspond to conditions observed in the western Baltic Sea during a period spanning $\sim 1$ decade, mainly during the 1990s. This choice originates primarily from the availability of data obtained during 1 monitoring effort, in which Zervoudaki et al. (2009) collected most of the environmental data. Values drawn from a single monitoring effort minimize apparent variability due to different sampling procedures. At the same time, it allows the use of established knowledge on $F$. vesiculosus depth distribution during that period for the validation of the model. The potential to apply the generated model in the case of locations other than the Baltic Sea where F. vesiculosus or closely related species have experienced decline in recent years, is restricted by the distinct abiotic (e.g. no tides, low salinity) and biotic (e.g. low biodiversity, phenotypic divergence) environment of the Baltic Sea, as this has been incorporated into the model. However, the framework and basic principles of this effort are rather general and could be easily implemented elsewhere, provided that the required knowledge on the functioning of the system's components is available.

Changes in the maximum depth of Fucus vesiculosus have been reported with regard to both the greatest depth where single plants can be found and 
the lower limit of the belts formed by dense algal stands. The 2 measures do not coincide and can differ to a considerable degree, as single specimens have been spotted at depths well exceeding the depth limit of belt formations (Kautsky et al. 1986). The model focuses on the physiology of single plants and the way this is affected by abiotic and biotic factors, while neglecting effects of population dynamics, which should be crucial in the processes of belt formation and preservation. Model results should therefore be compared against observations of the greatest depth where single plants can be found, rather than the depth limit of the algal belts.

The results of 2 monitoring efforts from the late 1990s, included in compilations of studies from the Baltic Sea (Torn et al. 2006, Schories et al. 2009), set the depth limit of single Fucus vesiculosus plants in the Bay of Kiel at 10 and $8 \mathrm{~m}$, respectively. The value of $9.28 \mathrm{~m}$, yielded here as the maximum depth limit of the algae, lies between these values and does not fall outside this range even when input parameters and external variables are varied within their preassigned ranges.

The relevance of our results for managing efforts, e.g. in a conservation context, should be viewed with caution. The greatest depths where single plants can be found are generally considered exceptions, not representative of the environment where dense stands can thrive if all factors are taken into account (Rohde et al. 2008). Therefore, the weak dispersal capacity of Fucus vesiculosus (Serrão et al. 1997) renders single plants at extreme depths irrelevant for the well-being of the ecologically more significant algal belts. Despite such putative limitations in dispersal, re-establishment of relatively isolated belts that had previously disappeared may happen rapidly (within 2 to $3 \mathrm{yr}$; Nilsson et al. 2004). The observed patchiness may also be attributed to the significant reduction of suitable substrate due to stone fishing (the systematic removal of stones from the seabed), rather than stress-induced inability to form distinct belts (Schories et al. 2009). In either case, the planned future incorporation of aspects of population dynamics into the model is something that should significantly broaden the scope of its descriptive ability.

No in situ measurements of monthly net growth rate of light-limited Fucus vesiculosus plants from the Baltic could be found, against which modeled $\mu_{c}$ values at $z_{L}$ could be tested. Data from shallower depths (Strömgren 1986, Wahl et al. 2010) agree with the year-round pattern of modeled $\mu_{c}$ in showing a peak between May and June, which follows a steep increase in the spring months and is followed by a more gradual decline during summer. The modeled $\mu_{c}$ at $z_{L}$, with minima in early spring and autumn, disagrees with observed growth rates that show 1 clear minimum in winter. The fact that this pattern is also observed in modeled irradiance levels at $z_{L}$ but completely disappears once phytoplankton is removed from the model or when $I$ is calculated at shallower depths (data not shown), indicates that this model pattern arises from a phytoplankton-induced reduction of available light. Its impact is only visible at depths where attenuation in the overlying water column renders light limiting. The disparities observed in modeled $\mu_{c}$ and $I$ values at $z_{L}$ in April and in the pattern of values simulated for summer are apparently the result of reproduction in the former case and the combined effect of respiration and epibiosis in the latter. In the model, respiration and epibiosis are also responsible for the pronounced September minimum in values of $\mu_{c}$ at $z_{L}$, owing to relatively high temperatures in the beginning of autumn.

In contrast to abiotic factors, among which no interactions were included in the way they affect algal growth, external biotic factors were credited with both antagonistic (increase in epibiosis leads to reduction in grazing) and synergistic (increase in ephemeral macroalgae leads to increase in grazing) effects, on top of plain additive ones (no interactions among the rest of the pairs of external biotic factors). The image drawn for the effects of abiotic factors is probably incomplete and could benefit from the incorporation of interactions among them. Although proportion-wise in accordance with the documented additive, antagonistic, and synergistic effects among biotic stressors on Fucus spp. (Wahl et al. 2011), the interactions among external biotic factors that are included in the model are obviously a subset of all interactions occurring in nature. It is not clear whether the restricted influence of those interactions on the model's outcome arises from this underrepresentation or indeed constitutes a feature of the system. The elucidation of their role in F. vesiculosus fitness and the way external biotic factors can modulate abiotic stress and in turn are modulated by it is an area where more research is needed, to reach the level of knowledge required for their substantial representation in a modeling effort.

Data on the effect of epibionts on Fucus vesiculosus growth rate suggest that the stress exerted on the algae is equivalent to a $2 \mathrm{~m}$ shift down the water column (Rohde et al. 2008). Although this is significantly larger than the epibiosis-related reduction in $z_{L}$ of $1 \mathrm{~m}$ predicted by the model, it should be noted that the study by Rohde et al. (2008) was restricted to the 
period from mid-August to mid-October, when epibiotic load is relatively heavy. Therefore, its results might overestimate the year-round effect of epibiosis on algal growth. The relatively small simulated impact of herbivory on growth rate originates mainly from its highly seasonal nature and the reduced palatability of light-limited plants. The importance of transitory outbursts in the number of consumers, arising from unusually favorable conditions, and their effect on F. vesiculosus (Nilsson et al. 2004) might be underestimated by the model. It should, however, be taken into consideration that such observations have only been made with regard to belt width and algal cover and not the depth limit of single plants. The impact of competition from ephemeral macroalgae has also been disregarded in the model, as it has been shown to primarily take effect during the recruitment phase of the plant's life history (Worm et al. 2001). Adult individuals appear insensitive to competition from ephemeral macroalgae, regardless of the production levels acquired by the latter (Bokn et al. 2002).

Many factors have been suggested to control depth penetration of Fucus vesiculosus, some of them playing a particularly significant role in specific areas or in particular periods in time. Setting issues of recruitment aside, most studies agree that the single most important factor determining the lower depth limit of the algae is light (Bäck \& Ruuskanen 2000, Eriksson \& Bergström 2005). This is corroborated by the results of the sensitivity analyses performed with our model. These indicate sea surface irradiance and chl $a$ concentration as the factors that have the greatest impact on modeled $z_{L \text {, }}$ while the model's output appears most sensitive to fluctuations of parameters associated with light attenuation and utilization $\left(\varepsilon_{0}\right.$ and $\left.\varphi_{g 0}\right)$. This also agrees with most studies, which identify increased light attenuation in the water column as the most prominent constituent of eutrophication in the Baltic Sea and is believed to have led to a widespread reduction of $F$. vesiculosus depth penetration (Kautsky et al. 1986, Eriksson et al. 1998). The fact that the model does not appear to be particularly sensitive to changes in temperature, which, among other factors, controls epibiotic load, corroborates studies ascribing a more important role to shading by phytoplankton in the decline of Fucus spp. than to epibionts, when it comes to plants near their depth limit (Vogt \& Schramm 1991, Rohde et al. 2008). The more subtle interactions between epibiotic load and its host algae have by no means been covered to an adequate degree here. The relatively high sensitivity of the model's output to variations of parameters associated with epibiosis ( $f$ and $h$ ) indicates the need for this interaction to be thoroughly investigated. The restricted response of the model's output to changes of salinity is not surprising for euryhaline species like F. vesiculosus, its competitors, grazers, and epibionts, while the negligible impact of nitrogen is in line with the limited role attributed to interactions among external biotic factors, as the effect of nutrients on chl a concentration outside of our scope and therefore not included in the model.

Despite the unambiguous role of light in determining the fate of established stands of Fucus vesiculosus, it has failed to predict the regeneration pattern of degraded algal belts (Torn et al. 2006). The same might hold true for predictions based on this particular modeling effort. The susceptibility of recruitment potential to factors determining zygote establishment and germling survival (Kautsky \& Serrão 1997) and the complex biotic interactions that are believed to modulate the way $F$. vesiculosus is affected by synchronous abiotic and biotic stressors (Wahl et al. 2011) are elements that are expected to play an important role in environments prone to disturbance. Hence, we expect that their incorporation into the model would greatly expand its ecological relevance. Given the highly stochastic nature of factors critical to the system's behavior and the imminent threat of climate change to push them near or past their current extremes, the application of risk analyses on probabilistic models of algal distribution could offer a unique opportunity for quantification of the effects expected to be incurred by environmental change.

Acknowledgements. We thank two anonymous reviewers and the editor for their valuable advice. Financial support was provided by the State Agency for Agriculture, Environment and Rural Areas of Schleswig-Holstein (LLUR).

\section{LITERATURE CITED}

Anders K, Möller H (1983) Seasonal fluctuations in macrobenthic fauna of the Fucus belt in Kiel Fjord (western Baltic Sea). Helgol Meersunters 36:277-283

Aneer G, Florell G, Kautsky U, Nellbring S, Sjöstedt L (1983) In-situ observations of Baltic herring (Clupea harengus membras) spawning behaviour in the Askö-Landsort area, northern Baltic proper. Mar Biol 74:105-110

> Bäck S, Ruuskanen A (2000) Distribution and maximum growth depth of Fucus vesiculosus along the Gulf of Finland. Mar Biol 136:303-307

> Bäck S, Collins JC, Russel G (1992) Comparative ecophysiology of Baltic and Atlantic Fucus vesiculosus. Mar Ecol Prog Ser 84:71-82

Beer A (1852) Bestimmung der Absorption des rothen Lichts in farbigen Flüssigkeiten. Ann Phys (Berlin) 86:78-88 
Berger R, Malm T, Kautsky L (2001) Two reproductive strategies in Baltic Fucus vesiculosus (Phaeophyceae). Eur J Phycol 36:265-273

Bergström L, Berger R, Kautsky L (2003) Negative direct effects of nutrient enrichment on the establishment of Fucus vesiculosus in the Baltic Sea. Eur J Phycol 38: 41-46

> Bokn TL, Moy FE, Christie H, Engelbert S and others (2002) Are rocky shore ecosystems affected by nutrientenriched seawater? Some preliminary results from a mesocosm experiment. Hydrobiologia 484:167-175

Brenchley JL, Raven JA, Johnston AM (1996) A comparison of reproductive allocation and reproductive effort between semelparous and iteroparous fucoids (Fucales, Phaeophyta). Hydrobiologia 326-327:185-190

Costanza R, d'Arge R, de Groot R, Farber S and others (1998) The value of the world's ecosystem services: putting the issues in perspective. Ecol Econ 25:67-72

> Dethier MN, Williams SL, Freeman A (2005) Seaweeds under stress: Manipulated stress and herbivory affect critical life-history functions. Ecol Monogr 75:403-418

Engkvist R, Malm T, Tobiasson S (2000) Density dependent grazing effects of the isopod Idotea baltica Pallas on Fucus vesiculosus L. in the Baltic Sea. Aquat Ecol 34: 253-260

Eriksson BK, Bergström L (2005) Local distribution patterns of macroalgae in relation to environmental variables in the northern Baltic Proper. Estuar Coast Shelf Sci 62: 109-117

Eriksson BK, Johansson G (2003) Sedimentation reduces recruitment success of Fucus vesiculosus (Phaeophyceae) in the Baltic Sea. Eur J Phycol 38:217-222

Eriksson BK, Johansson G, Snoeijs P (1998) Long-term changes in the sublittoral zonation of brown algae in the southern Bothnian Sea. Eur J Phycol 33:241-249

> Goecker ME, Kåll SE (2003) Grazing preferences of marine isopods and amphipods on three prominent algal species of the Baltic Sea. J Sea Res 50:309-314

Goldman JC, Carpenter EJ (1974) A kinetic approach to the effect of temperature on algal growth. Limnol Oceanogr 19:756-766

Haahtela I (1984) A hypothesis of the decline of the bladder wrack (Fucus vesiculosus L.) in SW Finland in 1975-1981. Limnologica 15:345-350

> Harley CDG, Hughes AR, Hultgren KM, Miner BG and others (2006) The impacts of climate change in coastal marine systems. Ecol Lett 9:228-241

> Jormalainen V, Honkanen T, Koivikko R, Eränen J (2003) Induction of phlorotannin production in a brown alga: defense or resource dynamics? Oikos 103:640-650

> Jormalainen V, Wikström SA, Honkanen T (2008) Fouling mediates grazing: intertwining of resistances to multiple enemies in the brown alga Fucus vesiculosus. Oecologia 155:559-569

Kangas P, Autio H, Haellfors G, Luther H, Niemi A, Salemaa $\mathrm{H}$ (1982) A general model of the decline of Fucus vesiculosus at Tvaerminne, south coast of Finland in 1977-81. Acta Bot Fenn 118:1-27

Kautsky L, Kautsky N (2000) The Baltic Sea, including Bothnian Sea and Bothnian Bay. In: Sheppard CRC (ed) Seas at the millennium: an environmental evaluation. Elsevier, Amsterdam, p 121-134

Kautsky L, Serrão EA (1997) Reproductive ecology in Fucus vesiculosus: a key species on rocky shores in the Baltic Sea. In: Abstracts of the Joint BMB 15 \& ECSA 27 Sym- posium, Mariehamn, Finland, 9-13 June 1997, p 11

Kautsky N, Kautsky H, Kautsky U, Waern M (1986) Decreased depth penetration of Fucus vesiculosus (L.) since the 1940's indicates eutrophication of the Baltic Sea. Mar Ecol Prog Ser 28:1-8

Korpinen S, Honkanen T, Vesakoski O, Hemmi A, Koivikko R, Loponen J, Jormalainen V (2007) Macroalgal communities face the challenge of changing biotic interactions: review with focus on the Baltic Sea. Ambio 36:203-211

> Lehvo A, Bäck S, Kiirikki M (2001) Growth of Fucus vesiculosus L. (Phaeophyta) in the northern Baltic Proper: energy and nitrogen storage in seasonal environment. Bot Mar 44:345-350

Lubchenco J (1983) Littorina and Fucus: effects of herbivores, substratum heterogeneity and plant escapes during succession. Ecology 64:1116-1123

Lund-Hansen LC, Sørensen HM (2009) Parameterization of surface irradiance and primary production in Århus Bay, SW Kattegat, Baltic Sea. Hydrobiologia 620:173-179

Lüning K (1990) Seaweeds: their environment, biogeography and ecophysiology. John Wiley, New York, NY

- Markager S, Sand-Jensen K (1992) Light requirements and depth zonation of marine macroalgae. Mar Ecol Prog Ser 88:83-92

Markager S, Sand-Jensen K (1994) The physiology and ecology of light-growth relationship in macroalgae. In: Round FE, Chapman DJ (eds) Progress in phycological research. Biopress, Bristol, p 209-298

Nilsson J, Engkvist R, Persson LE (2004) Long-term decline and recent recovery of Fucus populations along the rocky shores of southeast Sweden, Baltic Sea. Aquat Ecol 38:587-598

Nygard CA, Dring MJ (2008) Influence of salinity, temperature, dissolved inorganic carbon and nutrient concentration on the photosynthesis and growth of Fucus vesiculosus from the Baltic and Irish Seas. Eur J Phycol 43: $253-262$

> Oschlies A, Garçon V (1999) An eddy-permitting coupled physical-biological model of the North Atlantic. Part I: Sensitivity to advection numerics and mixed layer physics. Global Biogeochem Cycles 13:135-160

Pedersen MF, Borum J (1996) Nutrient control of algal growth in estuarine waters. Nutrient limitation and the importance of nitrogen requirements and nitrogen storage among phytoplankton and species of macroalgae. Mar Ecol Prog Ser 142:261-272

> Rohde S, Hiebenthal C, Wahl M, Karez R, Bischof K (2008) Decreased depth distribution of Fucus vesiculosus (Phaeophyceae) in the Western Baltic: effects of light deficiency and epibionts on growth and photosynthesis. Eur J Phycol 43:143-150

Schories D, Pehlke C, Selig U (2009) Depth distributions of Fucus vesiculosus L. and Zostera marina L. as classification parameters for implementing the European Water Framework Directive on the German Baltic coast. Ecol Indic 9:670-680

Serrão EA, Kautsky L, Lifvergren T, Brawley SH (1997) Gamete dispersal and pre-recruitment mortality in Baltic Fucus vesiculosus. Phycologia 36:101-102

> Strömgren T (1986) Annual variation in growth rate of perennial littoral fucoid algae from the west coast of Norway. Aquat Bot 23:361-369

Torn K, Krause-Jensen D, Martin G (2006) Present and past depth distribution of bladderwrack (Fucus vesiculosus) in the Baltic Sea. Aquat Bot 84:53-62 
van't Hoff JH (1884) Études de dynamique chimique. F. Muller, Amsterdam

Vogt H, Schramm W (1991) Conspicuous decline of Fucus in Kiel Bay (Western Baltic): What are the causes? Mar Ecol Prog Ser 69:189-194

Wahl M (1989) Marine epibiosis. I. Fouling and antifouling: some basic aspects. Mar Ecol Prog Ser 58:175-189

$>$ Wahl M (2008) Ecological lever and interface ecology: Epibiosis modulates the interactions between host and environment. Biofouling 24:427-438

Wahl M, Shahnaz L, Dobretsov S, Saha M and others (2010) Ecology of antifouling resistance in the bladder wrack Fucus vesiculosus: patterns of microfouling and antimicrobial protection. Mar Ecol Prog Ser 411:33-48

Wahl M, Jormalainen V, Eriksson BK, Coyer JA and others (2011) Stress ecology in Fucus: abiotic, biotic and genetic interactions. Adv Mar Biol 59:37-105

Weinberger F, Rohde S, Oschmann Y, Shahnaz L, Dobretsov S, Wahl M (2011) Effects of limitation stress and of dis-

Editorial responsibility: Hans Heinrich Janssen, Oldendorf/Luhe, Germany ruptive stress on induced antigrazing defense in the bladder wrack Fucus vesiculosus. Mar Ecol Prog Ser 427: 83-94

Witte JIJ, Zijlstra JJ (1984) The meiofauna of a tidal flat in the western part of the Wadden Sea and its role in the benthic ecosystem. Mar Ecol Prog Ser 14:129-138

> Worm B, Sommer U (2000) Rapid direct and indirect effects of a single nutrient pulse in a seaweed-epiphyte-grazer system. Mar Ecol Prog Ser 202:283-288

> Worm B, Lotze HK, Sommer U (2001) Algal propagule banks modify competition, consumer and resource control on Baltic rocky shores. Oecologia 128:281-293

$>$ Worm B, Barbier EB, Beaumont N, Duffy JE and others (2006) Impacts of biodiversity loss on ocean ecosystem services. Science 314:787-790

Zervoudaki S, Nielsen TG, Karstensen J (2009) Seasonal succession and composition of the zooplankton community along an eutrophication and salinity gradient exemplified by Danish waters. J Plankton Res 31:1475-1492

Submitted: January 18, 2012; Accepted: May 30, 2012

Proofs received from author(s): August 16, 2012 